\title{
HRTEM Study of Carbon SWNT: Assessing Purity and Defects as As-Grown Nanotubes Undergo Chemical Processing for Use in Polymer Nanocomposites
}

\author{
J.Y. Howe, ${ }^{*}$ L.F. Allard, * S. Viswanathan,** P.F. Britt,** S. Jesse, ${ }^{* * *}$, I.N. Ivanov,***, \\ A.A. Puretzky, ${ }^{* * *}$ and D.B. Geohegan*** \\ *Metals and Ceramics Division, **Chemical Sciences Division, and ***Condensed Matter Sciences \\ Division, Oak Ridge National Laboratory, Oak Ridge, TN 37831
}

Single-wall carbon nanotubes (SWNTs) are well-known for their remarkable electronic and structural properties, which promise to revolutionize various application areas, from nanoscale electronics to ultra-lightweight structural materials. This study utilizes HRTEM to characterize SWNT purity and defect levels throughout the many processing steps required to take as-synthesized SWNT to various uses in polymer nanocomposites. The SWNT investigated here were grown by the laser vaporization technique, which is one of the best methods to grow high-quality, high purity SWNT.[1] Using free-running Nd:YAG laser pulses, the as-grown material can be synthesized to $50-70 \mathrm{wt} \% \mathrm{SWNT}$, along with $12 \mathrm{wt} \% \mathrm{Ni}$ and Co catalyst metal particles, and the remaining amorphous and graphitic carbon (Figure 1a). For understandable chemistry and composites development, all the impurities need to be removed while keep the SWNT intact.

A multi-step purification procedure was developed to remove the amorphous carbon and metal particles to $\leq 0.2 \mathrm{wt} \%$ (Fig. $1 \mathrm{~b}$ ): the sample is first refluxed in $3 \mathrm{M}$ nitric acid for $16 \mathrm{~h}$, then heat treated at $400{ }^{\circ} \mathrm{C}$ for $2 \mathrm{~h}$ in air, followed by a concentrated $\mathrm{HCl} / \mathrm{H}_{2} \mathrm{O}$ wash. A second heat treatment is carried out at $450{ }^{\circ} \mathrm{C}$ for $3 \mathrm{~h}$, followed by a concentrated $\mathrm{HCl} / \mathrm{HF} / \mathrm{H}_{2} \mathrm{O}$ wash and a final dry in air in an oven at $100{ }^{\circ} \mathrm{C}$. It produces pure SWNT at $10 \mathrm{wt} \%$ yield rate with great repeatability. Thermal gravimetric analysis (TGA) data from the as-grown and purified samples show that the purified sample burns at $756{ }^{\circ} \mathrm{C}$ (wt \% and derivative wt \% plotted, Fig. 4). Yet the as-grown sample starts its weight loss as low as $325{ }^{\circ} \mathrm{C}$ and continues through out the entire temperature range. In addition to TGA, Raman, and inductively coupled plasma spectroscopy, HRTEM was undertaken extensively to evaluate the fine structures of the SWNTs at various stages, i.e., as-grown, after purification, and after functionalization. Samples were prepared by direct placing the SWNT material onto a holey carbon support film supported on a standard $3 \mathrm{~mm} \mathrm{Cu}$ grid. Specimens were examined in a Hitachi HF-2000 field emission TEM, operated at 200kV. The as-grown sample contained significant amounts of catalytic particles and amorphous carbon (Fig. 1a). The purified sample is nearly free of these impurities, and the SWNTs wall-quality remains pristine (Fig. 2a). Yet the functionalized SWNTs (by Piranha treatment) rendered the SWNT defective (Fig. 2b). Note that walls are full of defects. Functionalization treatments also reintroduce amorphous carbon.

SWNT nanocomposite films and fibers were prepared by spin casting or electrospinning. Various polymers, such as PMMA (polymethyl-methacrylate) and ODCB (ortho-dichlorobenzene) solution containing very low ( $0.125 \mathrm{wt} \%)$ to very high (6 wt. \%) purified SWNT were used. It is revealed in Figure 3 that bundles of SWNT are randomly distributed within the film. Imaging analysis is ongoing to determine the size and distribution of the SWNT bundles. [2]

References

[1] A. A. Puretzky, D. B. Geohegan, X. Fan, and S. J. Pennycook, Appl. Phys. Lett. 76 (2000) 182.

[2] Research sponsored by the Assistant Secretary for Energy Efficiency and Renewable Energy, Office of FreedomCAR and Vehicle Technologies, as part of the High Temperature Materials Laboratory User Program, Oak Ridge National Laboratory, managed by UT-Battelle, LLC, for the U.S. Department of Energy. 

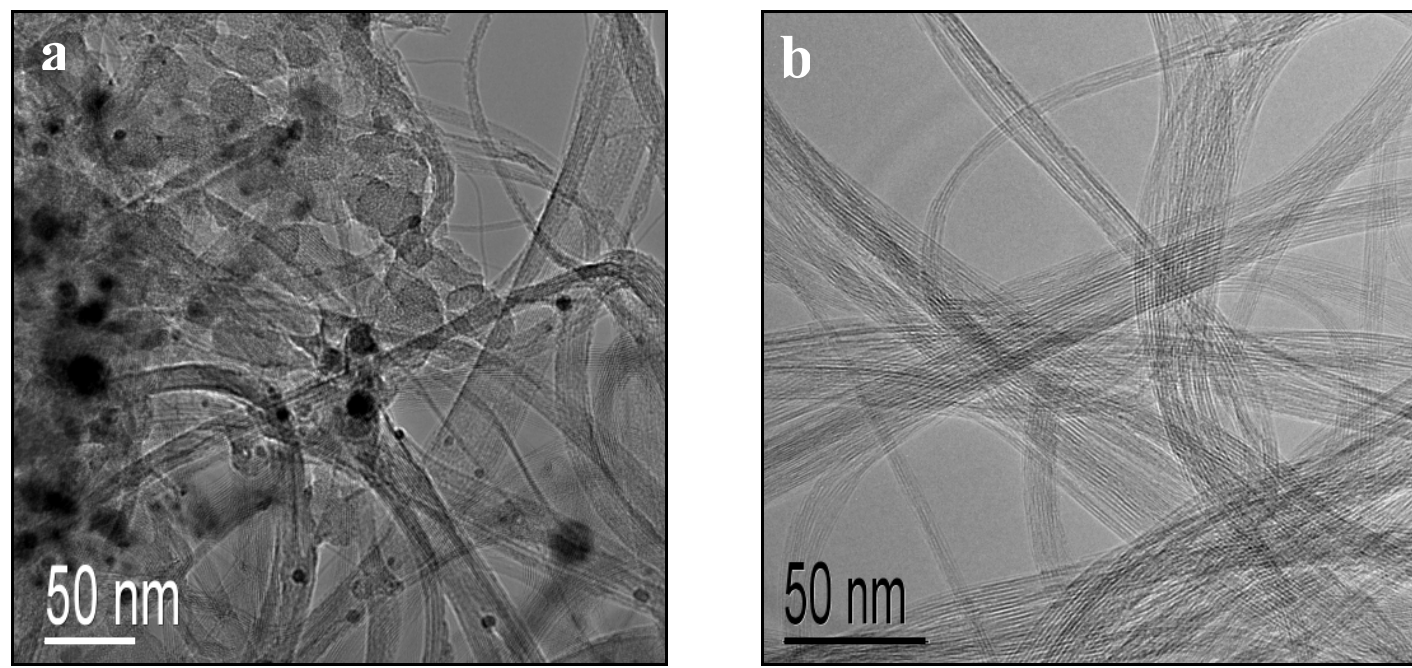

FIG. 1. (a) As-grown carbon SWNTs with catalyst metals and amorphous and graphitic carbon. (b) Purified SWNTs.
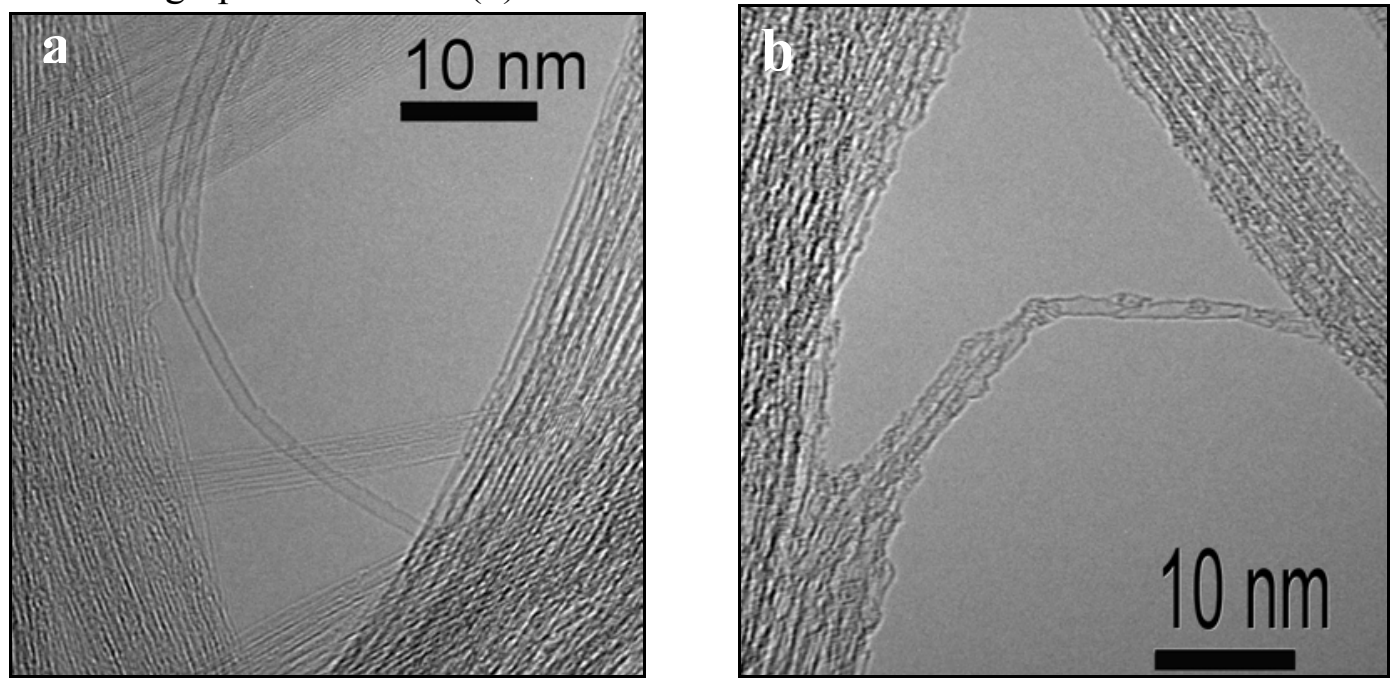

FIG. 2. HRTEM micrographs of SWNT: (a) after purification; and (b) after functionalization.

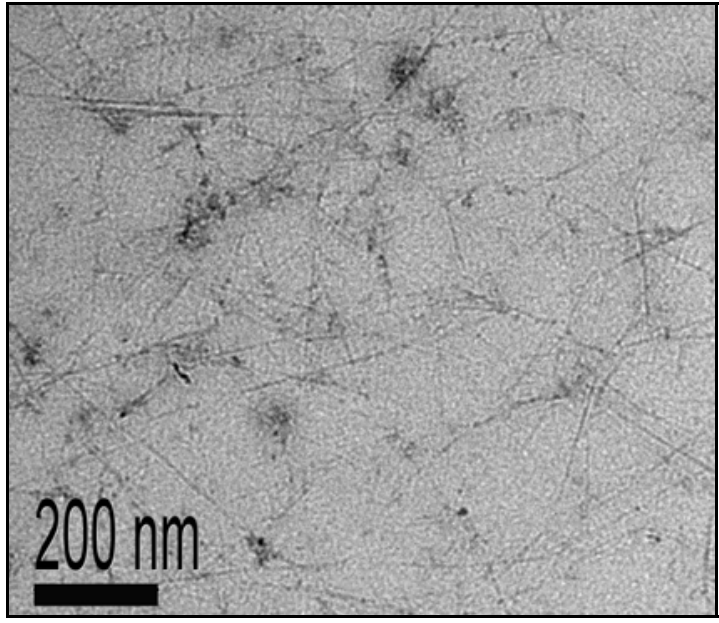

FIG. 3. SWNT/PMMA nanocomposite film, spun cast for $1 \mathrm{~min}$ at $2000 \mathrm{rpm}$.

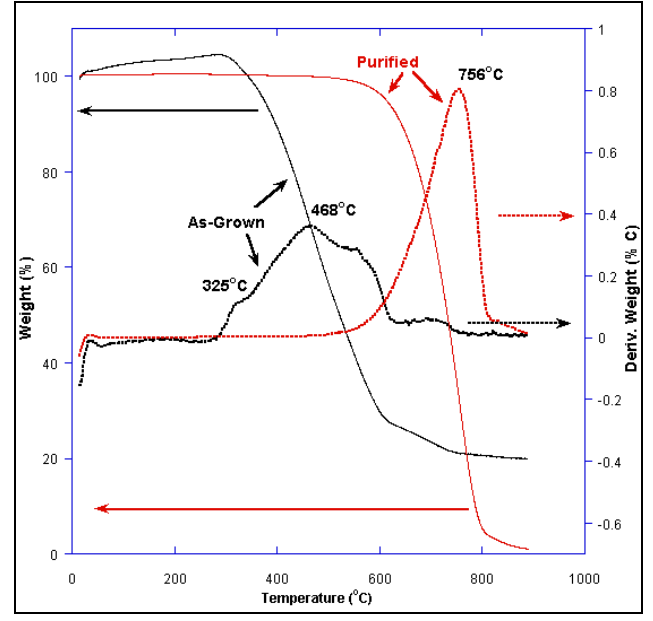

FIG. 4. TGA data from the as-grown and purified samples. 